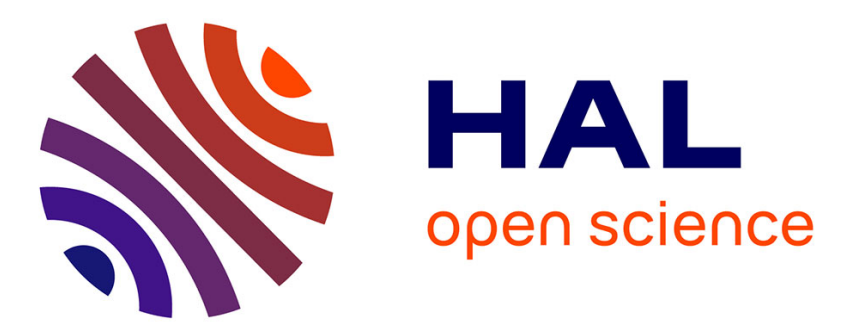

\title{
Imagery of local defects in multilayer components by short coherence length interferometry
}

Laurent Vabre, Vincent Loriette, Arnaud Dubois, Julien Moreau, A.C. Boccara

\section{> To cite this version:}

Laurent Vabre, Vincent Loriette, Arnaud Dubois, Julien Moreau, A.C. Boccara. Imagery of local defects in multilayer components by short coherence length interferometry. Optics Letters, 2002, 27 (21), pp.1899-1901. 10.1364/OL.27.001899 . hal-00661342

HAL Id: hal-00661342

https://hal.science/hal-00661342

Submitted on 19 Jan 2012

HAL is a multi-disciplinary open access archive for the deposit and dissemination of scientific research documents, whether they are published or not. The documents may come from teaching and research institutions in France or abroad, or from public or private research centers.
L'archive ouverte pluridisciplinaire HAL, est destinée au dépôt et à la diffusion de documents scientifiques de niveau recherche, publiés ou non, émanant des établissements d'enseignement et de recherche français ou étrangers, des laboratoires publics ou privés. 


\title{
Imagery of local defects in multilayer components by short coherence length interferometry
}

\author{
L. Vabre, V. Loriette, A. Dubois, J. Moreau, and A. C. Boccara \\ Laboratoire d'Optique Physique, Centre National de la Recherche Scientifique, Unité Propre de Recherche A0oo5, \\ Ecole Supérieure de Physique et de Chimie Industrielles, 10 rue Vauquelin, 75005 Paris, France
}

Received April 22, 2002

\begin{abstract}
We propose to image local defects inside multidielectric optical components by using a special configuration Linnik interference microscope, along with a CCD camera and a dedicated detection, to extract the amplitude scattered by the defects in the interference image. The use of a short coherence length source allows one to obtain interference only from a thin slice $(\sim 1 \mu \mathrm{m})$ within the observed object. The object is tilted to permit the use of a dark-field configuration to enhance the defect contrast. We describe the experimental setup and the detection scheme. Images that exhibit local point defects on the interfaces of various multilayer optical components (laser mirrors) are presented. (C) 2002 Optical Society of America

OCIS codes: $180.3170,110.4500,220.4840$.
\end{abstract}

Some thin-film research has been directed toward improving the quality of multilayer coatings. Standard control techniques, such as ellipsometry and scatterometry, ${ }^{1}$ provide powerful means for evaluating coating performance. However, these methods are inappropriate for the detection and study of pointlike defects inside buried structures. Inasmuch as point defects are usually the major sources of scattering in high-quality components, it is thus a crucial task to quantify the influence of such local defects on the structure of the coating and on its local characteristics. The main challenge is to obtain local information from a single buried interface of the component without physical contact with the component. This procedure would be particularly interesting at the end of the fabrication process, when the whole multilayer structure is present.

Phase measurement interferometry is a powerful method for obtaining surface profiles with nanometric resolution. ${ }^{2,3}$ However, in the case of multilayer components, such measurements are made with difficulty because the optical phase is integrated along the optical path through several layers. The apparent measured topography of a buried interface is a combination of the true topography and the topography of the layers located above it. The result is not simply a sum, because the incident wave front is not parallel to the observed surfaces; so obtaining the real topographies will require complex operations. To avoid this problem we propose to work with the interference signal's amplitude rather than with its phase. To enhance the contrast of this method, we use a dark-field configuration to avoid specular reflection on the interfaces.

The use of a short coherence length source enables one to obtain interference only from a thin slice. Use of this method is well known for the investigation of biological tissues (it is called the optical coherence tomography technique $)^{4}$ and for volume reconstruction. ${ }^{5,6}$ Here we propose to apply this principle to imaging the local defects of the interfaces inside a multidielectric structure.

The experimental setup is depicted in Fig. 1. It is based on a home-built Linnik interferometer. ${ }^{7}$ The Linnik configuration is more useful than the Mirau configuration, for example, for choosing the reference mirror and permitting the use of largenumerical-aperture objectives. As the amplitude of the light scattered by the local defects is weak, we use a low-reflectivity reference mirror $\left(R_{\text {ref }}=4 \%\right)$ to increase the contrast of the interference signal. The light source is a broadband tungsten halogen lamp that provides a coherence length close to $2.6 \mu \mathrm{m}$ at a central wavelength of $\lambda_{0}=800 \mathrm{~nm}$ (axial resolution, $L_{C} / 2=1.3 \mu \mathrm{m}$ ). The interference signal is detected by a dedicated multiplexed lock-in detection scheme that was described previously. ${ }^{8}$ The interference

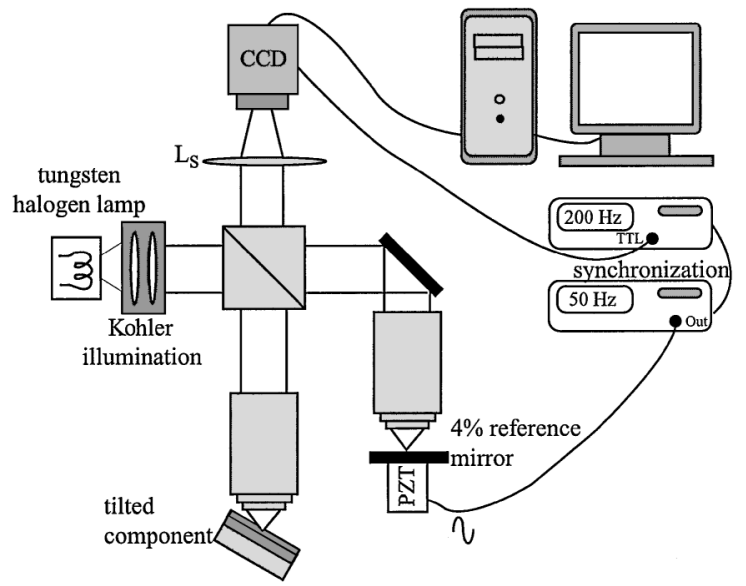

Fig. 1. Schematic representation of our Linnik interference microscope. Phase modulation is achieved by a piezoelectric transducer (PZT) synchronized with image acquisition by means of the two generators. $L_{S}$ is a lens that enables the objectives to work in infinite conjugation. TTL, transistor-transistor logic; Out, sinusoidal signal driving the PZT. 


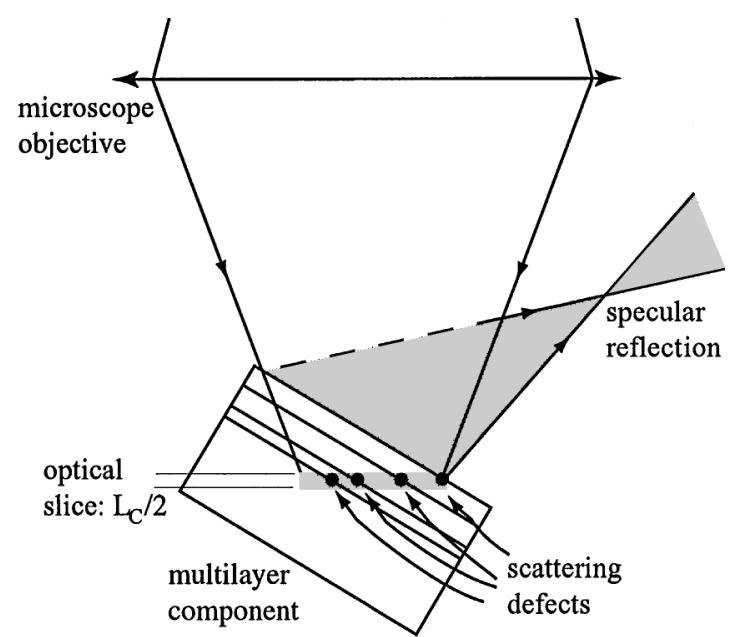

Fig. 2. Schematic of the dark-field configuration. The object is tilted to eliminate specular reflection. We obtain one echo per interface. $L_{C}$ is the coherence length of the light source $\left(L_{C} / 2-1.3 \mu \mathrm{m}\right)$.

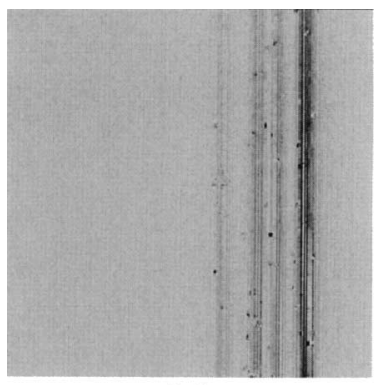

(a)

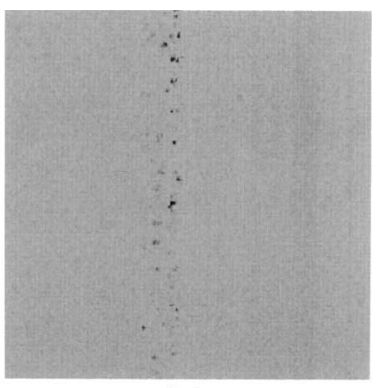

(b)
Fig. 3. Images of a multidielectric component. (a) Image before the limit angle. We can clearly observe one interferogram per interface. Some large defects have already been revealed. (b) Image in the dark-field configuration. No interferogram is visible. Point defects are well defined on the various interfaces. Exposure time, $2 \mathrm{~s}$. Field of view, $380 \mu \mathrm{m} \times 380 \mu \mathrm{m}$.

image is digitized on a CCD array $(256 \times 256$ pixels, 8 bits). To perform lock-in detection we introduce periodic phase modulation into the interference signal by means of a PZT that is sinusoidally modulated at frequency $f / 4$, where $f=200 \mathrm{~Hz}$ is the camera's frame rate. We then record four frames during each modulation period. As was previously demonstrated, ${ }^{8}$ the amplitude of the interference can be calculated from these four integrated values.

Our aim is to observe the local defects on the interfaces, but light that is due to the specular reflection on these interfaces (a few percent) will mask the signal induced by such defects (a few parts in $10^{6}$ ). For that reason we adopted a dark-field configuration to eliminate the specular reflection of the interfaces. Interference is produced between light reflected by the reference mirror and light scattered by the local defects. To obtain a dark-field configuration we tilted the multilayer component (see Fig. 2). With that configuration, we obtained different responses, each corresponding to an inteferogram for an interfaces.
Figure 3(a) shows the four responses from the four interfaces of a low-quality multidielectric component (two sequences of $\mathrm{SiO}_{2} / \mathrm{Ta}_{2} \mathrm{O}_{5}$ ) when the component was tilted before the dark-field limit. Figure 3(b) shows the same area tilted after the dark-field limit. We observe only the signal that is due to local defects whose locations are apparent. Figure 4(a) shows the response of a three-layer $\mathrm{CO}_{2}$ laser mirror recorded in a dark-field configuration. Figure 4(b) shows the sum of the amplitude values along the direction of the fringes $(y)$, where one peak per interface is observed.

We are able to detect an image of the defects, but the remaining difficulty is in calibrating the measurements to determine the sizes of the defects. We are not able to quantify our measurements yet. However, we can estimate the sensitivity limit of our setup. We found that, when the signal is integrated for less than a few seconds (a few hundreds of images) the main noise source is shot noise. For longer integration times, technical noises become dominant (thermal and mechanical drifts). We previously demonstrated ${ }^{8}$ that the lowest equivalent sample reflectance $R_{\text {min }}$ that can be detected by our technique is

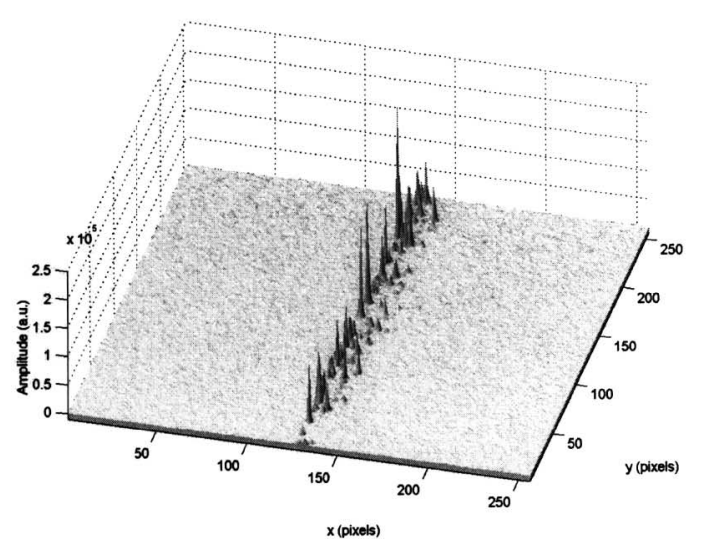

(a)

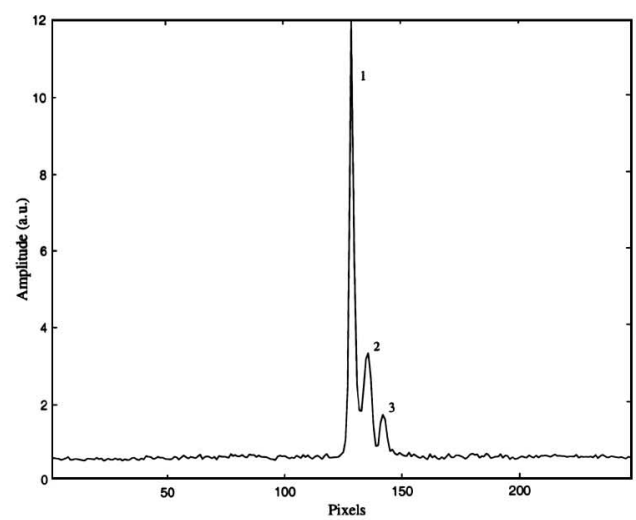

(b)

Fig. 4. (a) Response of a $\mathrm{CO}_{2}$ laser mirror. Three interfaces with various local defects have been detected. (b) Sum of the pixel values along the direction of the fringes (column). Three peaks, corresponding to three interfaces, are apparent. Exposure time, $2 \mathrm{~s}$. Field of view, $380 \mu \mathrm{m} \times 380 \mu \mathrm{m}$. 


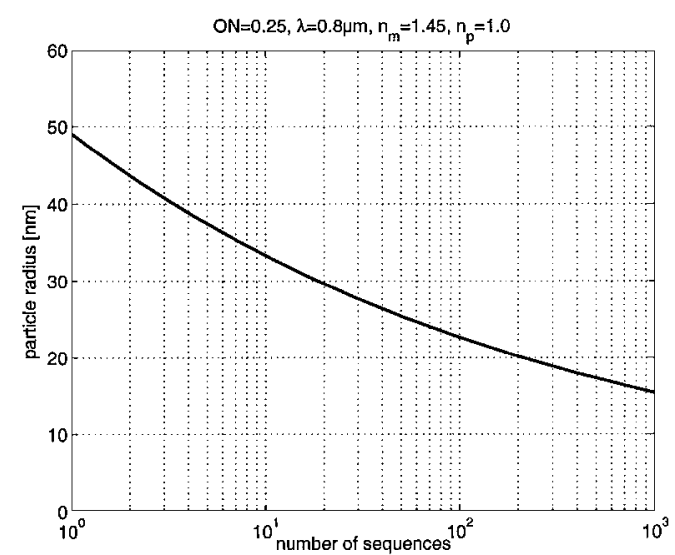

Fig. 5. Radius of the smallest detectable particle as a function of the number of sequences acquired ( 1 sequence $=$ total exposure time $4 / f \sim 0.02 \mathrm{~s}$ ). These values were obtained by use of Mie scattering theory; a spherical air bubble inside a silica substrate is assumed.

$$
R_{\text {min }}=\frac{\left(R_{\text {ref }}+2 R_{\text {inc }}\right)^{2}}{N \xi_{\text {max }} R_{\text {ref }}},
$$

where $R_{\text {inc }}$ is the part of the incoherent light backscattered on the CCD, $N$ is the number of summed images (representing exposure time $t=4 N / f$ ), and $\xi_{\max }$ is the number of photoelectrons per pixel required for saturation (the data sheet gives $\xi_{\max }=120,000$ for our CCD camera). The lowest equivalent sample reflectance is $R_{\text {min }} \sim 3 \times 10^{-7}$ for a single measurement (exposure time, $10 \mathrm{~ms}$ ). Using a simple Mie scattering model $^{9}$ of an air bubble $\left(n_{p}=1\right)$ trapped inside a silica substrate $\left(n_{m}=1.45\right)$, we can estimate the size $\phi_{\min }$ of the smallest detectable defect. The results of the numerical calculation are shown in Fig. 5 as a function of the number $N$ of acquired sequences. When one averages 100 sequences ( $2 \mathrm{~s}), 23$-nm-radius particles should be detected. An expression approaching $\phi_{\min }$ can be derived, where $\phi_{\min } \ll \lambda_{0}$ :

$$
\begin{aligned}
\phi_{\min }= & {\left[\frac{3}{4}\left(\frac{\lambda}{\pi}\right)^{4} \frac{R_{\min }}{n_{p}}\left|\frac{m^{2}+2}{m^{2}-1}\right|^{2}\right.} \\
& \left.\times\left(4-3 \cos \theta_{\max }-\cos ^{3} \theta_{\max }\right)^{-1}\right]^{1 / 6},
\end{aligned}
$$

where $n_{p}$ is the refractive index of the trapped particle, $m=n_{p} / n_{m}$, where $n_{m}$ is the material's refractive index, and $\theta_{\max }$ is the apparent aperture angle, which depends on $n_{m}$ and on the numerical aperture of the objectives. The sensitivity could be further improved by use of objectives with larger numerical apertures and also by shifting of the average incident wavelength toward the blue region of the spectrum [Eq. (2)]. The next step is to obtain a complete image, not only a line, of point defects on a particular interface. This could be done in one of several ways, such as simply by translating the sample along the $z$ axis and recording the lines to build the full image.

The authors are grateful to V. Reita and P. Piart for mechanical conception and realization. L. Vabre is grateful to the Délégation Générale pour l'Armement for financial support. This work is supported by the Centre National de la Recherche Scientifique (France). L. Vabre's e-mail address is vabre@optique.espci.fr.

\section{References}

1. J. S. Stover, Optical Scattering: Measurements and Analysis, 2nd ed. (SPIE Press, Bellingham, Wash., 1995), Chap. 6.

2. K. Creath, Prog. Opt. 26, 349-393 (1988).

3. S. S. C. Chim and G. S. Kino, Appl. Opt. 30, 2197 (1991).

4. D. Huang, E. A. Swanson, C. P. Lin, J. S. Schuman, W. G. Stinson, W. Chang, M. R. Hee, T. Flotte, K. Gregory, C. A. Puliafito, and F. G. Fujimoto, Science 254, 1178 (1991).

5. P. A. Flourney, R. W. McClure, and J. C. Wyntjes, Appl. Opt. 11, 1907 (1972).

6. A. Harasaki, J. Schmit, and J. C. Wyant, Appl. Opt. 39, 2107 (2000).

7. L. Vabre, A. Dubois, and A. C. Boccara, Opt. Lett. 27, 530 (2002).

8. A. Dubois, L. Vabre, A. C. Boccara, and E. Beaurepaire, Appl. Opt. 41, 805 (2002).

9. C. F. Bohren and D. R. Huffman, Absorption and Scattering of Light by Small Particles (Wiley Interscience, New York, 1998). 